\title{
Is Tracheostomy A Risk for Foreign Bodies Aspiration? -Case Report
}

\author{
Cristina Laza*1 and Sarv $\mathbf{M}^{2}$ \\ ${ }^{1}$ Assistant Professor, Maxillo-facial surgery Clinic, Romania \\ ${ }^{2}$ ENT surgeon, Romania
}

Submission: April 23, 2017; Published: May 04, 2017

*Corresponding author: Laza Cristina Otilia, ENT/OMF Clinic, SCJU , SF APOSTOL ANDREI, B-dul Tomis 145 , 900432, Constanta, Romania, Email: cristinaotilia@gmail.com

\begin{abstract}
Authors presents two patients with permanent tracheostomy after total laryngectomy, both with fragments from the tracheal tubes aspirated in the tracheo-bronchial tree, and well tolerated 6 and 3 months. Both patients require trachea-bronchoscopy with sedation and local anesthesia for extraction, and a treatment of the local infection with antibiotics, mucolytic, lavage with saline, aspiration, and new tracheal tubes. In one case with a difficult evolution after salvage surgery, and an infection with a total resistant to antibiotics Pseudomonas aeruginosa we use a silver tracheal tube because of his antiseptic properties. The evolution was good for both patients, in the end we inspect the inferior airways with a fiber optic bronchoscope. The authors compare the risk to aspirate in the tracheostoma a foreign body, compared with the normal patients.
\end{abstract}

Keywords: Tracheostoma; Tracheal Tube; Tracheo-Bronchial Foreign Body; Tracheo-Brohoscopy

\section{Case Report}

\section{Case No.1}

The first patient was a 52-year-old man, who underwent total laryngectomy 5 years ago for an squamous cell carcinoma of the larynx, followed by radiotherapy, well trained and capable to clean/and change the tracheal tubes without a problem and able to speak very well with esophageal voice. He came for a usual check up. At the clinical examination, no sign of local or regional recurrence, or a second primary cancer were observed and patient ask for a new cannula because of he broke one (tracheal tubes made are by polyvinyl, or silicone).

We check the stoma and trachea for complications like granulation tissue formation, tracheitis, tracheomalacia or stenosis and the patient claim that a part of the tube fall in the tracheobronchial three for at least 6 months but because he tolerated well -he came at the programmed control time. Thirst we didn't believe him, at the examination the patient was calm, without respiratory complains, no sign of infection like fever, the sonority of both lung was normal, but the tube was visible in the trachea standing on the carina, with some pus and crust around and inside [1-7].

In emergency we admit the patient in the Clinic and after a iv sedation and local anesthesia with lydocaine $10 \%$ we remove the tube using a rigid endoscope and a powerfull forceps, than we inspect the walls of the trachea and the bronchial tree for granulations, stenosis, atelectasis or infection also we aspirate all the secretions and finally insert a new tracheal tube. The chest X-ray was normal, patient support very well the procedure and the next day was discharge with an antibiotic, mucolytic, and new tracheal canules (Figure 1). The foreign body was in fact a piece of the tube because some laringectomised patients with experience cutt the lower part of the tracheal cannula to be shorter and easy to support [5].

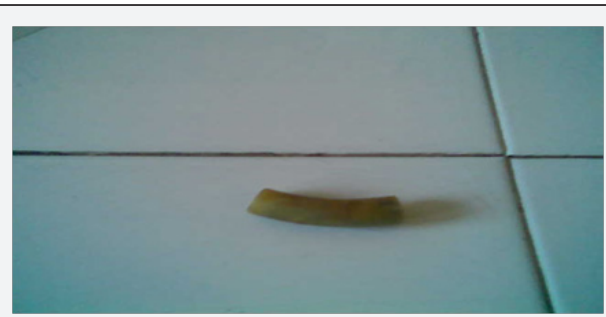

Figure 1: Foreign body -a piece from the tracheal tube.

Some patients prefer to use a special short silicone tube prescribed by the surgeon but expensive. Others with social and economic problems even the costs are supported by the health insurance, prefer to improvise. The usual PVC un cuffed tube we provide for each of them for free at demand. 


\section{Case No II}

A 65 years old patients with a total extended laryngectomy performed 4 years ago after an unsuccessful course of 40 Gy of radiotheraphy, completed after surgery with another 30 Gy and a difficult postoperatory evolution because of a pharyngeal fistula, use to presents every 6 month to follow-up , even after this long time. At the present check -up he accuse aspiration of the cannula broken when he attempt to change it, it but he recognize that he was drunk. He complain of cough and excessive purulent sputum without respiratory distress, for this reason he stay with the foreign body almost 3 month. We admit the patient in emergency and the X-ray of the chest shows us the tube in the right main bronchus [3].

In emergency after i.v. sedation and local lydocaine 10\% with a rigid endoscope we remove with a power full forceps the foreign body, than we make a lavage aspiration of the secretionsfor cultures for bacteria and fungi and we inspect the walls for granulations, stenosis or atelectasis, but nothing abnormal observe. Than we insert a new cannula -a silver one and start a course of antibiotics, steroids, mucolytic and aspirations till the tracheo-bronchitis was cure (Figure 2). At the end we check with a flexible bronchoscope the status of the trache and bronchial tree and everything was normal .We insert new tracheal tubes, well supported by the patient. The patient was discharged 10 days later and is still well (Figure 3).

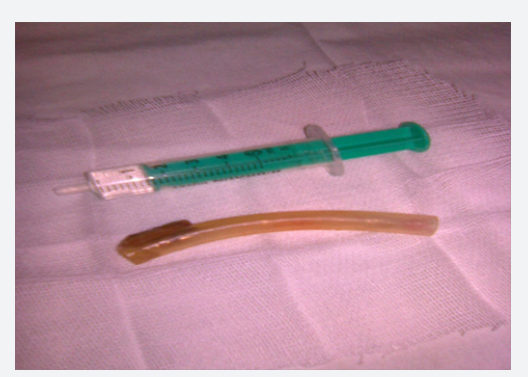

Figure 2: Ruptured tracheal tube after extraction.

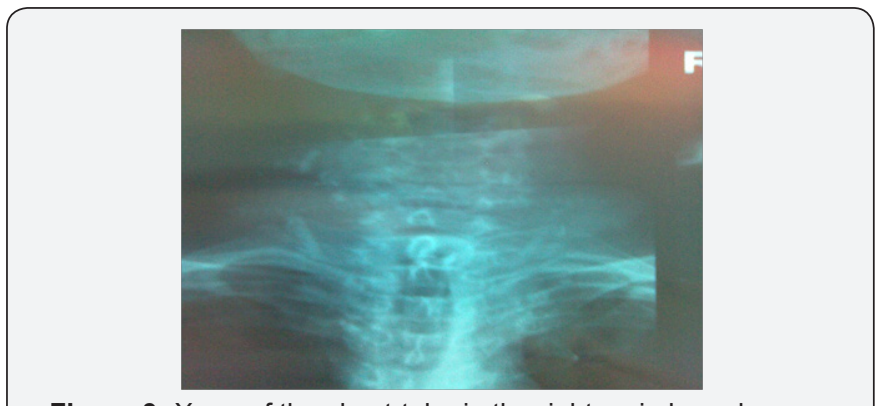

Figure 3: X-ray of the chest-tube in the right main bronchus.

\section{Discussion}

A. Tracheobronchial foreign body aspiration is an extreme emergency, seen in all ages and usually it requires urgent diagnosis and intervention.
B. Permanent tracheal stoma can be a risk factor for foreign body aspiration: metal and plastic objects, safety, scarf pins, fishing hooks, cockroaches, wood branches, nails, fractured tracheostomy cannula or the voice prosthesis [8].

C. The alcohol abuse can increase the risk of foreign body's aspiration, but also sedative and hypnotic drugs, convulsions, general anesthesia, intoxication, traumatic, unconsciousness, mental retardation, neurodegerative disorders also, some postoperative problems in laryngectomy or tracheostomy.

D. The position of the foreign body is related with construction of bronchial tree and posture of patient during aspiration, most common localization is right main bronchus because, is in more vertical position and with a bigger diameter. $2 / 3$ of foreign bodies are placed in main right bronchus.

E. The patients symptoms after aspiration are cough, dyspnea and hemopthisis or nothing. Occult foreign bodies remain undetected for months to years and often are misdiagnosed [9].

F. For the diagnosis, history, physical and radiological examination, and laboratory tests are necessary. On auscultation of the patient with foreign body aspiration, wheezing can often be heard and ipsilateral chest sounds are limited. X-ray -negative rates are between $8-80 \%$, CT scan is the best methods in this cases.

G. The flexible bronchoscopy is the first step to evaluate a patient with aspirated foreign body, playing a determinant role in diagnosis, and as method of extraction, if the patient is not asphyxiated in these cases the rigid bronchoscopy is necessary.

H. The rigid bronchoscopy remains the technique of choice to remove the majority of foreign bodies, but after total laryngectomy the rigidity of the neck after surgery, radiotherapy with impossible hyperextension it,s a problem, so the flexible bronchoscopy it's a good option. The extraction must be performed with general iv anesthesia or sedation with local contact anesthesia.

I. Exceptional thoracic surgery is necessary in old/impacted foreign bodies or in complications like pneumothorax, tracheo-eosophageal fistula or pulmonary abscess [10].

J. The complications after foreign body aspirations are frequent but are different with the type, localization, aspiration time of the foreign body and with underlying medical conditions.

K. other risk factors

a) Bronchiectasis , bronchial stricture 
b) Hemopthisis caused by inflammation and granulation tissue surrounding the foreign body

c) Persistent fever, chronic cough, recurrent lung infections,

d) Atelectasis,

e) Lung abscess,

f) Pneumothorax and pneumomediastinum can be seen frequently.

\section{Conclusion}

A. Although only a few cases of aspiration in patients with a permanent post laryngectomy tracheal stoma have previously been published, we think that the presence of a stoma should be added to a risk factors for foreign bodies aspiration in adults

B. On the other side tracheostomy protect from aspiration, patients with deglutition problems like stroke, or neurodegenerative disorders, cranial-cerebral traumas etc.

C. No definitive guidelines exist regarding the frequency of tracheostomy tube changes, In clinical practice, replacement schedules are quite variable, ranging from once a day to once a month. Frequent tube changes theoretically lessen the risk that granulation material and/or secretions will accumulate on the tube and partially block the airway.

D. It appears that PVC tubes tracheostomy tubes are prone to fracture at the neck plates if there is a manufacture defect or because of prolonged use, also voice prosthesis are described in literature as a foreign body.
E. Foreign body aspiration it,s a serious emergency for diagnose and treatment even that our patients were almost without symptoms.

F. Bronchoscopy is the gold standard for diagnose and treatment besides the clinical and radiological examinations even a CT scan in complications.

\section{References}

1. Limper AH, Prakash UB (1990) Tracheobronchial foreign bodies in adults. Ann Intern Med 112(8): 604-609.

2. Rehurek L (1975) Unusual complications caused by a foreign body in the tracheobronchial tree. Laryngoscope 85: 767-769.

3. Cannon CR (1982) Small tracheal stoma: An unusual cause of aspiration. South Med J 75(4): 512-513.

4. Finkelstein DM, Noyek AM, Friedberg J, Goldberg M (1989) Inhalation of a safety pin by a laryngectomized patient: A case report. J Otolaryngol 18(4): 189-192.

5. Lan RS, Lee CH, Chiang YC, Wang WJ (2017) Use of fiberoptic bronchoscopy to retrieve bronchial bronchial pertaining to or affecting one or more bronchi.

6. Bassoe HH, Boe J (1960) Broken tracheotomy tube as a foreign body. Lancet 1: 1006-1007.

7. Gupta SC (1987) Fractured tracheostomy tubes in the tracheobronchial tree: A report of nine cases. J Laryngol Otol 101: 861-867.

8. Majid AA (1989) Fractured silver tracheostomy tube: A case report and literature review. Singapore Med J 30: 602-604.

9. Hagibour A, Khan $\mathrm{ZH}$ (2007) Fracture and aspiration of metallic tracheostomy tube. Saudi Med J 28: 468.

10. Myers EN, Stool SE (1985) Complications of tracheostomy. In: Myers EN, Stool SE, Johnson JT, Eds. Tracheotomy. Churchill Livingstone, New York, USA, 147

\section{Your next submission with Juniper Publishers will reach you the below assets}

- Quality Editorial service

- Swift Peer Review

- Reprints availability

- E-prints Service

- Manuscript Podcast for convenient understanding

- Global attainment for your research

- Manuscript accessibility in different formats

( Pdf, E-pub, Full Text, Audio)

- Unceasing customer service

Track the below URL for one-step submission https://juniperpublishers.com/online-submission.php 